\title{
Crisis Management as Ethical Improvisation
}

\section{Chris MacDonald}

"Sometimes you have to play a long time to be able to play like yourself."
-Miles Davis

The skills involved in ethical decision-making, particularly in times of corporate crisis, bear remarkable similarities to the skills involved in musical improvisation. We gain important perspective on the ways in which organizations, in particular, handle crises if we frame the challenge in terms of the freedoms and constraints to which the improvising jazz or blues musician, for example, is subject.

On the face of it, ethics is fundamentally about rules. As a field of study, ethics is about engaging in critical, structured examination of the rules that ought to govern human behaviour and, in particular, human interaction. From the point of view of individual and institutional behaviour, ethics is about deciding which rules to follow and just what those rules require of us under what circumstances. The problem, of course, is that human life is complicated in a way that far exceeds the level of detail achieved by even the most complex and subtly nuanced set of rules we can imagine. And so even if we assume, for the sake of argument, that the rules of ethics are themselves relatively obvious and straightforward, the task of determining, from a practical point of view, how to apply those rules to real life is a nontrivial challenge.

Add to this the challenge posed by human progress, and by technological and cultural evolution. The ethical rules that made sense a hundred years ago, or even in some cases ten years ago, may not seem to fit modern needs. Just consider the change in scale our business corporations have seen over the last hundred years, or the vast acceleration in online commerce over the last decade. At the very least, the way old rules are applied may require considerable adaptation.

But the process of interpreting the demands of ethical rules, and indeed of adapting them to novel circumstances, is fraught with peril. In seeking to apply ethical rules, the individual or organization faces two serious challenges. One is a challenge to our capacity to reason: namely the challenge of figuring out, analytically, just what a particular rule or set of rules demands in a particular situation. To take a simple example, if one rule forbids lying, and another forbids hurting people's feelings, what should I do when telling the truth would be hurtful? That in itself is a hard intellectual problem. The second challenge lies in avoiding the temptation to allow self-interest to warp our reasoning. Ethical decision-making very often involves tension between our own interests and the interests of others. It is a challenge, in such situations, to avoid putting an unjustifiably high premium on our own preferences and needs. In interpreting and adapting rules to a particular situation, in other words, we all face the temptation to interpret the rules in ways that are friendly to our own interests. Such skewed interpretation is particularly common when it comes to making exceptions to rules. All sorts of mischief results when individuals and institutions engage in self-serving rationalization.

What we ought to seek, then, is a kind of rigorous and principled interpretation of the rules. We cannot avoid the need to interpret, to adapt, and even to make exceptions. But what we want is for such interpretation, adaptation, and exception-making to be done well and conscientiously.

The need for rigour and integrity in interpreting and applying ethical rules is particularly salient in moments of organizational crisis. In moments of crisis-either personal or organizational-the motivation to engage in self-serving rationalization may be extreme. Individuals may want to save face, and organizations may want to salvage their bottom line or reputation. Further, the heightened anxiety and emotional ferment that typically accompany crises seem liable to warp the decision-making of even the most diligent decisionmaker. And the need for clear ethical reasoning is particularly compelling here. In moments of crisis, it is important to determine the right thing to do because so much is often at stake. If there are indications that a company's product is killing people, lives are at stake. When a major environmental disaster strikes, ecosystems and livelihoods are at stake. When financial collapse looms, people's life savings are at stake. Regardless of the details of a particular situation, decision-making in times of crisis requires exceptionally careful attention to what ethics demand.

In addition to needing to do the right thing, a company in crisis needs to be able to explain to relevant stakeholders-often under the glare of media lights and cameras-just why it believes its action is justified, and just what pattern of reasoning led to that action. So companies facing crisis need not just to successfully interpret the relevant ethical rules and adapt them to a novel situation; they need also to be aware enough of 
the relevant rules and adaptations to explain them to a range of stakeholders. Clearly, that requires considerable skill.

We can learn a lot about the skill required for ethical decision-making in times of crisis by comparing such decision-making to another practice that involves nuanced deviation from the narrow confines of a set of rules, namely musical improvisation. I intend here no particular heavily-theorized understanding of improvisation. The understanding of improvisation that I have in mind is strictly that of the amateur lover of music, and of jazz and the blues in particular. What I see, when I see Miles Davis or Charlie Parker or BB King play, looks remarkably like what I want to see when I see a corporate executive managing a crisis.

There are five specific ways in which ethical crisis management is like musical improvisation. In each case, we see a fairly direct parallel between the skills required by diligent practitioners.

First, and perhaps most obviously, ethical crisis management needs to be creative. Just like musical improvisation, responding ethically to crisis requires a leap of imagination, rather than the mere ability to follow a prescribed "melody." The right thing to do-and the right thing to say-typically won't be obvious in a moment of crisis. Although various kinds of rules may apply pretty obviously, from the most general moral rules about honesty to the most complex industry-specific rules about things like conflict of interest or environmental remediation, the best response to a particular crisis situation, in all its complexity, is not going to be found in any pre-established script. Devising a course of action that is both ethically appropriate and capable of being explained well to relevant stakeholders is going to require that decision-makers adapt to the situation and exercise some moral imagination.

Secondly, ethical crisis management, while inevitably creative, must nonetheless be grounded in structure. Musical improvisation, while creative and spontaneous, is rarely random or arbitrary. For a musician, improvisation typically means pushing in new and creative directions-varying melody, rhythm, etc.- within the bounds of an underlying structure of some sort. That structure provides focus for the musician's improvisational creativity. Consider also the way many jazz musicians make use of "targeting," which involves playing the most important tones of a given chord. This implies a respect for structure. Similarly, an organization in crisis is going to want to draw upon the relevant ethical rules and principles, as well as its own basic ethical structure, consisting of things like its "Code of Ethics" and its "Mission, Vision, and Values" statements. A "Code of Ethics," if taken seriously, provides the underlying structure for an organization's overall pattern of behaviour-it is the unifying thread, like the melody of a musical composition. It provides the underlying structure, a structure from which crisis may force the organization to deviate, but a structure that should ideally still be recognizable as underlying its behavior even in crisis.

Next, like blues or jazz improvisation, responding ethically to crisis characteristically requires collaboration. Improvising musicians take their cues from, and draw inspiration from, each other. The best improv arguably happens among musicians who "get" each other and who trust each other. Improvisation can, of course, be a solitary activity for the solo artist. But when more than one musician is on stage, the activity is necessarily collaborative. The members of a jazz ensemble aren't just playing on the same stage - they are playing together. And the soloist relies, for example, on the rhythm section to sustain the fundamentals of the composition so that he or she has a structure from which to deviate, and to which to return. Likewise, response to ethical crisis is going to require close and effective collaboration between senior leadership, the company's technical experts, and perhaps individuals in charge of ethics-and-values or compliance policy and training.

Fourth, ethical responses to crisis must be grounded in knowledge. In music, amateurs are unlikely to do well at improvising; indeed, their attempts at "improvisation" may be difficult to distinguish from a series of beginner's mistakes. The expert musician, on the other hand, knows how to play the expected notes, and knows how to stick to the melody, but consciously (if sometimes intuitively) chooses to deviate. The CEO guiding her organization through a crisis must likewise work from knowledge: knowledge of the nature of ethical obligation, knowledge of her company's own values, and knowledge of the interests of various stakeholders.

Finally, to respond well to ethical crisis requires a good degree of confidence in using the relevant tools, concepts, and vocabulary. A master jazz musician reaches for unexpected notes and makes it look easy, natural. When improvisation is awkward, it tends to be obvious both to the performer and the audience. Good improv is natural, not forced. Likewise, the CEO responding to crisis needs confidence and a degree of comfort with the material at hand. To respond well to ethical challenges requires that the CEO be comfortable talking about ethics and about moral responsibilities to various stakeholders. She needs the confidence that comes from having thought about such matters before. She needs to be able to speak 
fluently the language of ethics, in the same way that the jazz master moves fluidly through the notes of a solo.

In all of these ways, the practice of acting ethically in response to crisis is like musical improvisation. Musical improvisation involves creative deviation from an underlying musical structure, and excelling at improv requires that the musician have a strong foundational knowledge of music and of her instrument, and the confidence and self-assurance to use that knowledge, supported by a collaborative ensemble. Likewise, the CEO guiding her firm ethically through a crisis must adapt creatively to a novel situation while staying true to fundamental underlying ethical structures, and if she is to do well at this, she must have knowledge of the relevant ethical principles, be comfortable working with and talking about them, and function well within a collaborative team environment.

The analogy between musical improvisation and ethical crisis management is not, of course, perfect, and the way this analogy plays out in particular sorts of crises warrants closer examination than is possible here. And it is clear that there are significant differences between the kinds of improvisation suited to musical performance, on one hand, and corporate management, on the other. Perhaps most obviously, the stakes in instances of corporate crisis are generally considerably higher than they are in music. If the musician improvises badly, the result is likely to be embarrassment; if the CEO improvises badly at the wrong moment, lives could be lost. This also means that the musician enjoys far greater leeway to experiment. The jazz soloist can afford to take huge risks, musically speaking, and that is likely the only way to push his art form forward. The CEO, on the other hand, can only improvise within limits. She simply is not free, ethically, to throw caution to the wind. Unlike musical rules, ethical rules are designed to protect central human interests. Interpretation of them, and deviation from them, must be done with all due caution.

Whatever its limits, the analogy here between music and crisis management is arguably more than just descriptive, more than a mere observable similarity. The analogy with musical improvisation is a useful way of framing the challenge faced by organizational managers in times of crisis. It is appropriate, I think, for such managers to picture themselves playing in a jazz ensemble, giving a performance guided by musical theory and rooted in a masterful understanding of melody, but seeking always and only the very best ways to deviate from the rigid dictates of that melody's structure. Ethics should be thought of as requiring decision-making that is neither rigid nor random. And responding ethically to crisis, in particular, requires a sound understanding of the relevant ethical principles, along with confidence and willingness to adapt them responsibly to the needs of the present situation.

Nero may have fiddled while Rome burned, but if he had been engaging in proper crisis management, he would have been thinking carefully about not just the tune he was playing, but how to improvise suitably to suit the situation.

\section{Notes}

${ }^{1}$ On the topic of self-serving rationalizations on the part of individuals, see Heath, and for an institutional perspective, see Ketola.

\section{Works Cited}

Heath, Joseph. "Business Ethics and Moral Motivation: A Criminological Perspective." Journal of Business Ethics 83.4 (2008): 595-614. Print.

Ketola, T. (Tarja). “Corporate Psychological Defences: An Oil Spill Case.” Journal of Business Ethics 65.2 (2006): 149-161. Print. 